\title{
Differenz
}

Revista internacional de estudios heideggerianos y sus derivas contemporáneas

AÑO 5, NÚMERO 4: JULIO DE 2018. ISSN 2386-4877 - DOI: 10.12795/Differenz.2018.i04.05

[pp. 77-91]

Recibido: $18 / 01 / 2018$

Aceptado: 05/06/2018

\section{Las Überlegungen VII-XI. El inicio de un proceso que pasa por tres fases.}

\section{The Überlegungen VII-XI. The beginning of a process that goes through three phases}

\author{
Alejandro Rojas Jiménez \\ Universidad de Málaga
}

Resumen:

Este trabajo pretende situar el inicio de la Spätphilosophie Heideggers en torno a la toma de conciencia de un "error" confesado en las Überlegungen VII-XI. Se propone partir de aquí para reconstruir la ruptura con su etapa anterior y para sugerir una clasificación de distintas etapas dentro de esa Spätphilosophie Heideggers que se piensa habitualmente e injustamente, añadiría yo- sin distinciones ni matizaciones dentro de lo que generalmente se ha designado como filosofía del Heidegger II.

Palabras Clave: Heidegger; Heidegger II, Überlegungen 


\section{Abstract:}

This paper aims to situate the beginning of the spätphilosophie Heideggers around the awareness of an "error" confessed in the Überlegungen VII-XI. It is proposed to start from here to reconstruct the rupture with its previous stage and to suggest a classification of different stages of the spätphilosophie Heideggers, which is usually thought -unjustly, I would say- without distinctions or qualifications, in waht generally is designated as the philosophy of the Heidegger II.

Keywords: Heidegger; Heidegger II; Überlegungen

\section{Introducción: El reconocimiento de su error.}

Las recientes aparecidas Überlegungen, los conocidos como los Schwarze Hefte, y cuyo estilo se asemeja al de una suerte de diario personal de pensamiento, han causado un gran interés, a veces incluso un revuelo impropio del mundo académico; con grandes historias como el caso Figal en Friburgo. Poco a poco, y conforme el acercamiento más fácil y rentable (el de las calumnias y las renuncias) se vaya enfriando, será posible ir sacando a la luz -sin necesidad de sentirse denunciado por antisemita- las grandes posibilidades hermenéuticas que estas reflexiones heideggerianas brindan para la comprensión de la filosofía de Heidegger. En este trabajo quiero acudir al segundo de los volúmenes, aparecidos en la GA 95, el de 1938/39, para mostrar en qué medida su análisis desapasionado puede brindarnos posibilidades hermenéuticas para comprender su viraje, el llamado paso al Heidegger II.

Mi intención en este trabajo será concretamente: llamar la atención sobre un momento crucial en la vida de Heidegger, que habría salido a la luz en este segundo volumen de los Schwarze Hefte, y que abriría desde una óptica biográfica una interesante clave para entender el fin, en el sentido de la latina meta, de aquella concepción aún fenomenológica del tiempo que caracterizaría al Ilamado Heidegger I. Al tiempo que, pues detrás de todo final se abre un nuevo comienzo, el inicio de algo nuevo ${ }^{1}$ que generalmente es conocido como Heidegger II.

Emulando el gesto del traductor al español de los volúmenes, que decía que la tesis central del primero de ellos podría ser que lo propio de la esencia no es definirse ni consolidarse, si no irradiarse y campar ${ }^{2}$, me gustaría atreverme a proponer a su vez una tesis central para este segundo volumen sobre el que quiero llamar la atención. A mi juicio,

1 Cfr., Überlegungen XI/53, GA 95.

2 Cfr., A. CIRIA, “Los 'cuadernos negros' de Heidegger”, Claves de razón práctica 247 (2016). 
si se aceptara algo así como la posibilidad de precisar una tesis central de las reflexiones en él contenidas, diría que esa tesis central debería decir algo así: que la historia de la filosofía es la historia de los grandes empujones ${ }^{3}$. Según esta tesis la filosofía, la historia del pensar occidental, dependería del modo en el que ha ido sabiendo atajar esos empujones. Esta idea que con el tiempo derivará en la filosofía de los acontecimientos, cuando los empujón es nos los den ya los hombres, sino una determinada concepción del ser que sacude la situación concreta de la filosofía, obligándola a responder.

Toda esa reflexión corre paralela a una preocupación bastante evidente por lo que hace que un filósofo/una filosofía ocupe un lugar prioritario en la historia del pensar occidental. Y que esta preocupación se desarrolla coherentemente con cierta toma de conciencia heideggeriana -bastante temprana- de su "error". Si bien, él mismo nos aclara en estas reflexiones lo que debemos entender aquí por errar. Aquí error no tiene las connotaciones que todos los hombres buenos y virtuosos ${ }^{4}$ hubieran esperado; esos que se han escandalizado tras la publicación del primer volumen. En realidad, va en esta otra línea: la tesis de Heidegger sería más bien que el errar es el auténtico "camino" de la filosofía, en tanto que sólo los "errantes" son capaces de adentrarse en "la noche del extravío en que consiste preguntar"7 filosóficamente, desprotegidos del frío ${ }^{8}$. Heidegger es rotundo al relacionar aquellos empellones de la historia de la filosofía con esta errancia y extravío cuando sentencia que: "el calado de una filosofía se mide -caso de que a eso se lo pueda llamar medir- en función de su fuerza para errar"9.

No será desde luego la última palabra acerca del modo en el que Heidegger piensa la historia de la filosofía. Se abre más bien un camino, que llevará a la filosofía del Seinsgeschick, que aquí ya se deja ver de forma inicial bajo la expresión Geschichte des Seyns. Heidegger inicia pues, lo diré así, un proceso de reflexión sobre su lugar en la historia que corre paralelo a un proceso de reflexión sobre su "error". Lo que se abre a partir de ahora es un proceso largo, donde podemos reconocer distintas etapas y fases,

\section{3 Überlegungen VII/1, GA 95.}

4 Algunos porque parecen pensar que la historia de la filosofía debiera ser la historia de los "más buenos" o los más "valiosos", y estuviera en cuestión, por así decirlo, su derecho a formar parte de dicha historia. Este asunto es bastante llamativo y una señal muy evidente de los tiempos curiosos por los que pasamos en la academia.

5 Überlegungen VII/37, GA 95.

6 Überlegungen VII/50, GA 95.

7 Überlegungen VIII/84, GA 95.

8 Cfr. Überlegungen VIII/84, GA 95.

9 Überlegungen VII/19, GA 95. 
en el que Heidegger cada vez va comprendiendo mejor su error, su lugar en la historia $y$, por supuesto, la historia misma de la filosofía. El lugar al que todo esto conduce, el lugar donde se funden finalmente todos estos elementos, el nuevo telos que se abre tras aquella meta, es en la llamada Geviert, tan incomprendida a menudo por la Academia, incapaz de reconocerla como lo que a mi juicio es: la última palabra del pensamiento ontológico de Heidegger.

Para entender bien el modo en el que Heidegger intenta en un principio dar forma a estos elementos tenemos que recordar que ya en el 36 había iniciado la redacción de aquel Beiträge zur Philosophie, la que podría ser considerada como la obra inicial de esa nueva filosofía ya no estrictamente fenomenológica. Y que ese mismo año había retomado contacto con el Freiheitsschrift de Schelling. No es arbitrario ni causal: la herramienta conceptual que le permitirá expresar filosóficamente estas ideas acerca del "error" y los "empujones" que le llevarán a la llamada Kehre, es justamente la filosofía de Schelling. Concretamente su distinción entre fundamento y existencia, desde la que intentará pensar el ser-como Schelling- de un modo histórico: epocalmente. Esto permitiría, por decirlo resumidamente, justificar una filosofía con distintos inicios sin hacerlo desde la visión ilustrada de "corrección de errores" (el método de la verdad) ${ }^{10}$, sino desde la necesidad de transformación que tiene un -lo diré schellingianamente- "fundamento real y vivo", que nos obliga .empujándonos o demandándonos- a una tarea "errante".

Lo diré del siguiente modo, los empujones podrían ser pensados posteriormente -es decir: cuando éstos no los den los individuos, sino el ser mismo- a partir de Schelling como aquella "fuerza oscura y originaria que subyace a toda existencia"11. Heidegger hablará de demanda y de llamada como claves interpretativas para entender nuestra pertenencia a la historia del pensar occidental.

Que detrás del paso heideggeriano a la historia del pensar, que es la historia del ser, está Schelling, lo ha mostrado nuevamente, y creo que es el trabajo más reciente en este sentido, Markus Gabriel en su Unvordenkliches Sein und Ereignis. Der Seinsbegriff beim späten Schelling und beim spoäten Heidegger, donde insiste en la conexión entre ambos a partir de esta misma clave hermenéutica: la sustitución de la concepción lógica del ser por un geschichtlichen Seinsbegriff ${ }^{12}$ que Heidegger habría aprendido a pensar a partir de la distinción schellingiana entre fundamento y existencia, la misma que el idealista

10 El otro gran referente será en este nuevo inicio Nietzsche, el filósofo contra la voluntad de verdad. 11 Freiheitsschrift, SW VII, 441.

12 M. GABRIEL, "Unvordenkliches Sein und Ereignis. Der Seinsbegriff beim späten Schelling und beim spoäten Heidegger", en HÜHN-JANTZEN (ed.), Heideggers Schelling-Seminar (1927/28), Schellingiana 22/VIII (2011), 81-112, p. 82; p. 110. 
utilizaría para pensar, utilizaré una expresión de Borbujo: "la estructura temporal que define el mundo"13. No olvidemos que el rasgo general de la Spätphilosophie Schellings es que cuando Schelling piensa a Dios como "acto originario" lo que esencialmente sucede es que, como decía Fuhrmans, "la dimensión de la historia lo determina ahora todo"14.

Heidegger se fija en este "principio productivo" del que habla Schelling como productividad incondicional, que genera productos cuando alguien, esto lo añadirá el Heidegger del "pastor del ser", escucha su llamada. Pues bien, desde aquí se pueden leer con facilidad las claves del pensamiento del Ilamado Heidegger II: su noción de Ereignis, su noción de verdad como dejar-ser (de Wegmarken), sus referencias a la libertad del claro en Holzwege, su noción de Ungrund en Der Satz von Grund... Estas nociones podrían ser interpretadas como un intento de recuperar aquella idea -de basamento schellingiano- de que la historia de los hombres es expresión (la existencia) de un libre deseo de saber-responder (fundamento) en el que Heidegger habría depositado -lo que se intentará mostrar en este trabajo- su intento de autocomprender y autojustificar su particular extravío, en tanto que ese deseo de libertad -lo divino que hay en nosotros- nos empuja a encaminarnos por el camino errante del extravío en el que no se calculan (una razón que ya no es ratio) las consecuencias, sino que tan sólo se pretende dar rienda suelta a esa llamada interna que nos demanda a aventurarnos y, en esa misma medida, ser expresión -un elemento más- de lo único que existe: el interminable juego histórico de desocultamientos y ocultamientos incesantes que tiene lugar en la realización del "deseo de saber", cuya realización no es otra cosa que la historia de la filosofía, y que Heidegger acabará por designarlo como un juego de entrecruzamientos de cuatro regiones a las que denomina: tierra, cielo, mortales e inmortales ${ }^{15}$.

Las posibilidades hermenéuticas que abre el enfoque expuesto irían por este camino: se permitiría una aclaración y división de las fases de ese llamado Heidegger II. A la aclaración, justificación y exposición de esto último quiero dedicar los esfuerzos de esta investigación, que debe acabar con una propuesta clara de división (por obras y por fechas) de la Spätphilosophie Heideggers.

13 F. P. BORBujo, Schelling. El sistema de la libertad, Herder, Barcelona, 2003, p. 698.

14 Funrmans, H., Schellings Philosophie der Weltalter. Schellings Philosophie in den jahren 18061821. Zum Problem des Schllingschen Theismus, Suhrkamp, Düsserldorf, 1954, p. 301.

15 Para una profundización en esta cuadratura cfr., A. ROJAS, La Cuadratura. La última palabra del pensamiento ontológico de Heidegger, SPICUM, UMA, Málaga, 2009. 


\section{El punto de inicio: el reconocimiento de un error sin aparente aceptación de responsabilidad ni culpa.}

Confiesa Heidegger en estos cuadernos negros, que había cometido un error al apoyar el nacionalsocialismo. Heidegger, en estas fechas, cree incluso que en 1934 había "roto" con el nacionalsocialismo. Es lo que explica su gran asombro ante la comisión de depuración, incluso posiblemente la razón de su colapso ${ }^{16}$. Debe decirse sin embargo que dicha ruptura debe ser matizada: su error, a lo que se refiere el filósofo alemán, consistiría en haberse confundido con respecto "al carácter y la fuerza" del nacionalsocialismo. O dicho de otra manera, con haberlo entendido mal, con haber creído que podría ser un nuevo comienzo.

Este error, pues, dista mucho de conducirlo a un arrepentimiento. Su error, aparentemente, no habría sido según él haber promovido -digámoslo sobriamenteinhospitalidades. No hay ninguna reflexión acerca de las posibles consecuencias morales de sus actos. Sí que es constante, desde luego su preocupación por lo que hace que un pensador merezca un hueco en la historia del pensar. En este sentido, él sabe que ha dado un fuerte empujón a la historia, al poner sobre la mesa -debemos decirlo así para que sea entendido en toda su crudeza- que promover la inhospitalidad es el camino necesario para conseguir realizar aquella geistigen Auftrag, sirviéndonos de la expresión de Safranski ${ }^{17}$, y que podríamos caracterizar como liberación espiritual de Europa, en tanto que la promoción de la inhospitalidad sería un modo privilegiado de conseguir despertar la llamada de la conciencia y la apropiación de la existencia; según la idea de existencia auténtica/propia defendida en SuZ.

Cierta visión de este asunto es la que lleva a Faye a decir que Heidegger ha introducido el nazismo en la filosofía ${ }^{18}$, o a Quesada a pensar, en una línea similar, que la filosofía de Heidegger es una ontología nazi ${ }^{19}$. Yo, en realidad, creo entender la cuestión de otro modo. De un modo que quizás resulte aún más perverso si cabe: Heidegger creía, y se dio cuenta pronto de su error, que la inhospitalidad promovida por el nacionalsocialismo podría servir para el comienzo de un mundo nuevo, donde fuera posible la existencia auténtica. La promoción de la inhospitalidad y la angustia las defiende Heidegger, lo diré en pocas palabras, sin necesidad de llegar a ser nazi. Lo que Heidegger era, es más bien un existencialista que ha creído que debía promover la inhospitalidad, como si la historia

16 Cfr., L. TAMAYO, "El colapso de Heidegger de 1945-1946. Reflexiones acerca del autor y su obra", l'école lacanienne de psychanalyse 3 (2001), pp. 161-184.

17 SAFRANSKI, Un maestro de Alemania. Heidegger y su tiempo, Tusquets, Barcelona, 1997, p. 276. 18 E. FAYE, Heidegger et l'introduction du nazisme dans la philosophie, Albin Michel, París, 2005.

19 J. QUESADA, «Martin Heidegger y la exigencia política del conocimiento: una raza dura», Isegoría, 43 (2010), 545-563, p. 546. 
le hubiera encomendado la posibilidad de intervenir en ella misma, de dirigirla. Esto es lo que está expresado en la exitosa formulación de Pöggeler de 1985: “Den Führer führen"20.

Lo diré así: la dialéctica existencialista entre autenticidad e inautenticidad expresada en SuZ debemos tenerla en cuenta (haciendo notar que no es lo mismo el nacionalsocialismo en el 33 que en el 45) para entender el compromiso político que Heidegger adquiere con el nacionalsocialismo. Quiero decir, el convencimiento de Heidegger de que no puede haber una existencia auténtica en una existencia cómoda y segura. Para un análisis de la promoción de la inhospitalidad remitiré a un trabajo previo: "La ciudad inhóspita promovida por Martin Heidegger"21. En esta ocasión, para evitar demorarnos mucho, recordaré sencillamente la siguiente clara e indicativa cita de SuZ:

El encontrarse, se dijo en el pasaje anterior, hace patente "cómo le va a uno". En la angustia le va a uno "inhóspitamente". En ello encuentra inmediatamente su expresión la peculiar indeterminación de aquello cabe lo cual se encuentra el "ser ahí" en la angustia: el "nada y en ninguna parte". Pero "inhospitalidad" quiere decir al par "no estar en su casa". Ya al hacer las primeras indicaciones fenoménicas acerca de la estructura fundamental del "estar ahí" y al dilucidar el sentido existenciario del "estar en" a diferencia de la significación categorial de la "interioridad", se definió el "estar en" como un "habitar en", un "estar familiarizado con". Este carácter del "ser en" se hizo visible de una manera más concreta con la cotidiana publicidad del uno, que introduce en la cotidianidad del término medio del "ser ahí" la aquietada seguridad en sí mismo y el "estar en su casa" comprensible de suyo. La angustia, en cambio, saca de nuevo al "estar ahí" de su cadente absorberse en el "mundo". Queda quebrantada hasta las entrañas la cotidiana familiaridad. El "estar ahí" es singularizado, pero como "estar en el mundo". El "estar en" pasa al "modo" existenciario del "no en su casa". Esto es lo que se quiere decir al hablar de "inhospitalidad"22.

Heidegger puede haber acabado intentando promover en la práctica esa inhospitalidad que, teóricamente, nos llevaría a entender la existencia como ese sujetarse en medio de la nada de la que habla en su Was is Metaphysik ? $^{23}$. Frente a Heidegger, Zambrano habla

20 O. PÖGgelER, "Den Führer führen. Heidegger und kein Ende", Philosophische Rundschau 32 (1985), 26-67, 67.

21 A. ROJAS, "La ciudad inhóspita promovida por Martin Heidegger", Isegoría 47/julio-diciembre (2012), 499-517.

22 Sein und Zeit, en GA 2, § 40.

23 Was ist Metaphysik?, en GA, 9, p. 115. 
de la piedad ${ }^{24}$, seguramente esa que le faltó a Heidegger y que echó en falta Lévinas desde los campos de concentración. Sin piedad ninguna, Heidegger se lanzó a proponer la angustia desde fundamentos propios. Y por eso, como cuenta Gadamer, lo que le hizo percatarse de su "error" fue la visión de los nuevos funcionarios ${ }^{25}$, es decir: descubrir que el nacionalsocialismo estaba promoviendo un discurso identitario concreto. Todos los nuevos funcionarios eran iguales ¿qué autenticidad había ahí?, y lo peor, todos parecían confiar ciegamente en su Führer que les brindaba una renovada seguridad. El resultado era pues lo contrario a lo que Heidegger pretendía. Más que apropiación lo que nos encontramos es la huida que Sartre caracterizó magistralmente en su L'enfance d'un chef. No pretendo con eso salvar a nadie de nada: no es desde luego ningún tipo de salvación decir que éste fuera presumiblemente el motivo que precipitara su "ruptura".

En estas fechas de los cuadernos negros, la conciencia de su error no parece tener nada que ver con la esperada conciencia de culpabilidad. Seguramente porque esto sólo pueda ocurrir después del juicio de depuración, cuando es puesto frente a sí mismo. Y seguramente, esa paulatina asunción de culpa sea la que explique el devenir de la filosofía tardía de Heidegger. En estas fechas, sin embargo, todavía se cree -él sí lo creía así- "a salvo", porque cree que basta con que su apoyo haya sido "desde motivos propios" 26.

\section{Sobre la autocomprensión de su error}

El juicio de depuración, al juzgarlo culpable, le hará tomar conciencia -con el tiempode que apoyar el nacionalsocialismo desde criterios propios no lo hacen menos nacionalsocialista de lo que lo eran los "inauténticos" nazis; la toma de conciencia a la que le conducirá la resolución posterior y definitiva. Es culpable sin excusas de haber promovido una "inhospitalidad" (que es el término del que él habla en su obra filosófica) que llegará a transformarse en terror. Sólo este terror puede hacer que surja esa tristeza (que ocupa un lugar central en la filosofía del Heidegger II) que, haciéndonos sentir estúpidos, sea el comienzo de una nueva filosofía; que no puede ser la misma que la que nace desde la admiración (Aristóteles), la duda vital (Agustín de Hipona) o la búsqueda de certezas (Descartes), al nacer por el contrario desde la necesidad de poner en relación su

24 Cfr., R. RODríGUez, "Naufragio, inhospitalidad, entrañas. María Zambrano ante Ortega y Heidegger", Aurora 12 (2011), 41-55.

25 Cfr., H-G. GADAMER, Hermenéutica de la modernidad. Conversaciones con Silvio Vietta, Trotta, Madrid, 2004, p. 41.

26 Überlegungen, XI, 53, GA 95. 
existencia (la auténtica: recordemos que no se deja arrastrar al nacionalsocialismo, sino que lo afirma desde criterios propios) con su historia, su Geschichte.

Heidegger cree sin embargo, en este temprano 1934-6 de estas reflexiones, haber obligado a la historia a hacerse cargo -lo diré con su expresión- de su empujón. Él seguirá pensando mucho después que debemos promover la inhospitalidad. Se puede ver por ejemplo en 1951, cuando propone -frente a la urgencia de construir viviendasque aprovechemos la ocasión para pensar qué significa habitar. Vaya a ser, diré -si se me permite- con algo de sorna, que hagamos viviendas demasiado cómodas y seguras y volvamos a impedir las condiciones de posibilidad para la existencia auténtica.

Sí se puede notar, sin embargo, un cambio de actitud: frente a su etapa nacionalsocialista, ahora su actitud se ha serenado. Lo que llevará a la defensa del pensamiento meditativo frente al calculador ${ }^{27}$. Pero desde luego la obra de referencia aquí debe ser la anterior Brief über den Humanismus, de 1946, por su defensa de la escucha como actitud fundamental. De la misma fecha es Der Spruch des Anaximander, donde profundiza en esta misma línea al hablar del uso ${ }^{28}$; cabría decir: de cómo la historia nos usa.

En esta fase, Heidegger parece haber comprendido que se debe renunciar a todo voluntarismo. Quiere retrasar el pensamiento frenético y calculador que nos asegure refugios, lo cual parece muy acorde con la fase de la serenidad, mas sin embargo, al promover tal cosa, sigue empeñado en extender la inhospitalidad. No ha dejado atrás su loca pretensión; sigue empeñado en lo que considera que es su "histórica misión"29.

Habrá sin embargo un cambio significativo en 1953, en Identität und Differenz, cuando lo por pensar deja de situarse en dependencia de nuestras actitudes, lo que ocurre como desarrollo de la filosofía de las señales de 1949 (donde aparece la primera formulación madura de la Cuadratura). Desde este momento, no podemos decir ya que seamos nosotros los que damos empujones, sino que la epocal copertenencia de pensar y ser sencillamente acontece. Lo podríamos quizás decir así: los empujones los debemos esperar de esas señales que nos iluminan enseñándonos el camino que debemos tomar para corregir, enderezar o quizás tan sólo seguir recorriendo afrontando, en cualquier caso, la guerra con nosotros mismos y nuestras miserias.

27 Gelassenheit, Neske, Pfullingen, 1959, p. 15.

28 Holzwege, GA 5, p. 368.

29 por decirlo usando la conocida expresión de nuestro Ortega y Gasset en El tema de nuestro tiempo, en Obras completas, 3, pp. 151ss. 


\section{Una clasificación de la filosofía de Heidegger II}

Si se aceptan las premisas de la exposición anterior para la concepción de la Spätphilosophie Heideggers, cabe hacer una división muy clara de las fases de esta filosofía. Merece la pena recordar que el propio Heidegger nos propone una clasificación en 1962, cuando menciona distintos estadios "provisionales" ${ }^{30}$ y que la clasificación que aquí propondremos coincide con las fechas señaladas por Heidegger; que eran las siguientes: Brief über den Humanismus (1946), Einblick in das, was ist (1949), Die Frage nach der Technik (1953) e Identität und Differenz (1957).

Antes de exponer esta clasificación que proponemos también conviene recordar escuetamente los siguientes datos, en armonía con lo dicho en el apartado anterior:

1. Que el momento de ruptura con la filosofía fenomenológica anterior se sitúa en la comprensión de su "error" en 1934, pero que podríamos retrotraerla incluso a 1933 siguiendo la interpretación recogida de Gadamer.

2. Que en 1944 aparece una actitud más serena que supone un giro con respecto al intento de promover la inhospitalidad. Esto desemboca, en 1946, en Brief über den Humanismus, coincidiendo con el primer hito dentro del cambio que reconoce Heidegger.

3. En 1949 aparece la formulación madura de das Geviert, en Einblick in das, was ist, también señalado por Heidegger como uno de esos estadios provisionales. De la actitud de la escucha se pasaba entonces a reconocer que no estaba en nosotros (en ninguna de nuestras actitudes) la posibilidad del cambio. Esto desemboca más adelante en Die Frage nach der Technick de 1953.

4. Después de 1955, de la Gelassenheit, se profundiza en esta nueva óptica para entender cómo acontece lo que puede ser pensado. Lo que desemboca en Identität und Differenz, de 1957. En esta etapa se habría producido el siguiente cambio con respecto a la etapa inicial: el reconocimiento de que estamos desarmados ante los extravíos, los grandes errores, la discordia, la noche, el desgarro que consume... Estos son términos empleados por Heidegger en aquellas reflexiones (por supuesto siempre teniendo a mano de un modo muy explícito a Nietzsche, el hombre más allá del bien y del mal), y daban forma a la noción central de "los errantes" (die Irrenden), que en su extravío y desorientación son quienes crean un espacio contra lo aplanado y lo carente de espacio (Raumlose). Pero ahora, ya no se trata de atreverse a errar, ni siquiera a 
aceptar una demanda histórica. Ahora, el protagonismo ha sido arrebatado a nuestro poder. Más que atrevernos a errar, resulta más bien que nos hemos visto ya errando.

Pues bien, mi clasificación, en atención de lo dicho de las fases de la Spätphilosophie Heideggers es la siguiente:

1. Como fase inicial señalaría su particular comprensión de su error. Las fechas de esta etapa irían desde 1934, es decir desde su dimensión del rectorado, hasta 1939, tomando como razón para seleccionar esta fecha los "cuadernos negros" VII-XI que aquí hemos comentado.

2. La primera fase propiamente, es decir, en lo que desemboca esa concepción de su error, es en un período que habría ido gestándose desde 1936. En esta fecha la preocupación por Heidegger, siempre de la mano de Schelling, se centra en el inicio y la posibilidad de un nuevo comienzo. Las obras de referencia aquí serían: Beiträge zur Philosophie, y sus lecciones sobre Schelling, también de 1936. Esta fecha abarcaría hasta 1941-2, es decir hasta los Hölderlins Hymne(n), donde aparece la primera formulación de la Cuadratura, en Der Rhein. Allí la cuadratura es designada como Geburt-Lichtstrahl, Noth-Zucht. Podríamos retrotraer el origen de la Cuadratura incluso a 1935, a Einführung in die Metaphysik, donde formula la cuadratura de sollen-denken, werden-schein ${ }^{31}$. Heidegger habría visto ya en 1935 lo que Mattéi designa como La quadruple énigme d'être ${ }^{32}$. Pero 1935 es a mi juicio una fecha demasiado temprana para hablar de la Cuadratura. Propongo retrasar ésta hasta los himnos a Hölderlin porque es muy importante construir la Cuadratura -más allá de una posible fase inicial anterior- sobre la siguiente convicción que se produce con estos himnos: "a través de la llegada de los nuevos dioses en toda la historia, la existencia de los alemanes de este mundo deberá mostrar un nuevo camino y crear una nueva firmeza" ${ }^{33}$. Podríamos denominar a esta fase pues: la fase del nuevo comienzo.

3. Segunda fase: la fase de la formulación madura de das Geviert. En 1949, en Einblick in das, was ist, se recoge en Das Ding la que será la formulación definitiva de la Cuadratura. En ella se recogen ya esos dioses, y también los mortales, aunque como Menschen, que habían aparecido también en Hölderlins Himmel und Erde. Y llegaría hasta 1951, Bauen, Wohnen, Denken. En este período Heidegger se ha serenado, y busca situar el origen de ese nuevo comienzo fuera de nuestros "empujones". Y, sin embargo, aún cree que todo depende de nuestra actitud: de la escucha (Brief über den

31 Einführung in die Metaphysik, en GA 40, p. 204.

32 Cfr., J-F. MATTÉı, Heidegger. Lènigme d l'être, PUF, París, 2004.

33 Hölderlins Hymnen "Germanien" und "Der Rhein", en GA 39, p. 93. 
Humanismus, 1946). Le falta serenidad, la de 1955 (Gelassenheit), esa que le habría permitido entender que la cuestión no es sólo la de no apresurarse, que es lo que pide en 1951 ante la urgencia de hacer viviendas.

4. Tercera y última fase: la fase de la Willenslosigkeit. Yo la situaría en 1953, en Die Frage nach der Technick. Aquí cuando busca las causas y analiza nuestro mundo ya sabe que sólo un Dios podrá salvarnos. Lo que desemboca en Entsprechen, 1955, es decir, la toma de conciencia de que no se trata de escuchar ni de ser usados, sino de que siempre "pertenecemos" de un modo u otro a ese juego de entrecruzamientos que en 1957, en Identidät und Differenz, lleva a Heidegger a sustituir la conocida anwesenlassen anterior por la reflexión -lo diré heideggerianamente- en torno al acontecimiento de la mutua copotertenencia entre pensar y ser. O dicho de otra manera del anwesenlassen se pasa al Seinlasen ${ }^{34}$ de 1962, donde el papel de nuestra actitud pierde el protagonismo, que ahora recae en la estructura cuádruple de la desocultación ${ }^{35}$. Se produce, pues, una suerte de desubjetivización o de ontologización, según la cual no es necesario promover ya ninguna situación propicia. Deja de hablar de promociones y pasa a hablar en su lugar de cómo viviendo en el mundo podemos observar las señales que nos iluminan demandando nuevas posibilidades ${ }^{36}$. Se produce, en expresión del propio Heidegger una suerte de reivindicación de la Willenslosigkeit ${ }^{37}$ que yo, en otros lugares he intentado mostrar que estaban aún en continuación con la Spätphilosophie Schellings, quien también quería pensar el inicio, el tema que, desde 1934 ha colmado la atención de Heidegger. En la obra más significativa al respecto de Schelling, en su Philosophie der Mythologie, hablará de lo Potenzlose ${ }^{38}$. Más adelante, en su Philosophie der Offenbarung, dice Schelling que "no se trata de pensar una realidad precedente a toda posibilidad" 39 , sino -continúa diciendo- "el comienzo de todo pensar real", que no puede ser "el mismo pensar", sino lo que produce el pensar. Esta búsqueda schellingiana acerca del origen del querer pensar, y que lo conduce al originario abismo de la razón del Akt der Freiheit que es aquel Urseyn entendido como absolute Prius y que como tal sólo empíricamente, a posteriori se podría reconocer. Esto es suo modo el camino de Heidegger, pero que en lugar de a una Philosophie der

34 Cfr., Zur Sache des Denkens op. cit., p. 40.

35 Un estudio ampliado de esta cuestión se puede ver en A. ROJAS, La Cuadratura. La última palabra del pensamiento ontológico de Heidegger, SPICUM (=Estudios y ensayos 119), Málaga, 2009.

36 Cfr., La Cuadratura op. cit.

37 Cfr., Erläuterungen zu Hölderlins Dichtung, en GA 4, esp. 46.

38 Cfr., A. RoJAs, Das Potenzlose, Olms, Hildesheim, 2014.

39 Philosophie der Offenbarung, SW XIII, 162. 
Offenbarung lo conducen a la filosofía de das Geviert y de la Willenslosigkeit, punto de arribo de un viraje que había empezado con la toma de conciencia de un "error" que cada vez fue comprendiendo mejor, hasta descubrir la in-mundicia de la existencia humana, reinterpretando de un modo muy maduro aquel "estar-en-el-mundo" de 1927.

\section{Bibliografía}

a) Bibliografía citada de Heidegger:

a.1) En aquellos casos en que ha sido posible se ha citado según la versión de las obras completas editada por Klostermann, es decir: Gesamtausgabe (GA), editada por Klostermann en 4 secciones: los escritos publicados, las lecciones, los escritos no publicados y una carta sección para seminarios, cartas y los cuadernos negros. Esta edición sigue un plan previsto, pero permanece aún sin acabar.

Sein und Zeit, 1927, GA 2.

Einführung in die Metaphysik, 1935, GA 40.

Erläuterungen zu Hölderlins Dichtung, 1936-1968, GA 4.

Holzwege, 1935-1946, GA 5.

“Was ist Metaphysik?", 1929, en Wegmarken, 1919-1958, GA, 9.

Hölderlins Hymnen "Germanien" und "Der Rhein", 1934/5, GA 39.

Überlegungen I-VI, 19311-1938, GA 94.

Überlegungen VII-XI, 1938-39, GA 95.

a.2) Otras obras de Heidegger citadas por otras ediciones:

Gelassenheit, 1955, Neske, Pfullingen, 1959.

Zur Sache des Denkens, 1962/4, Niemayer, Tübingen, 1976.

b) Bibliografía citada de Schelling: 
Las obras de Schelling han sido citadas según la edición de las obras competas de August Schelling, es decir: Sämmtlichen Werken (SW), ed. August Schelling, Stuttgart y Augsburgo, 1856 ss.

Philosophische Untresuchungen über das Wesen der menschlichen Freiheit und die damit zusammenhängenden Gegenstände (=Freiheitsschrift), 1809. SW VII.

Philosophie der Offenbarung, 1841/2. SW XIII.

c) El resto de la bibliografía utilizada:

BORBujo, F.P., Schelling. El sistema de la libertad, Herder, Barcelona, 2003.

CIRIA, A., "Los 'cuadernos negros' de Heidegger", Claves de razón práctica 247 (2016)

FAYE, E., Heidegger et l'introduction du nazisme dans la philosophie, Albin Michel, París, 2005.

funrmans, H., Schellings Philosophie der Weltalter. Schellings Philosophie in den jahren 1806-1821. Zum Problem des Schllingschen Theismus, Suhrkamp, Düsserldorf, 1954, p. 301.

GABRIEL, M., "Unvordenkliches Sein und Ereignis. Der Seinsbegriff beim späten Schelling und beim späten Heidegger", en Hühn-Jantzen (ed.), Heideggers Schelling-Seminar (1927/28), Schellingiana 22/VIII (2011), 81-112.

gAdAmer, H-G., Hermenéutica de la modernidad. Conversaciones con Silvio Vietta, Trotta, Madrid, 2004, p. 41.

MATTÉı, J-F., Heidegger. Lènigme d l'être, PUF, París, 2004.

PÖGGELER, O., "Den Führer führen. Heidegger und kein Ende”, Philosophische Rundschau 32 (1985), 26-67.

ORTEGA Y GASSET, J., El tema de nuestro tiempo, en Obras completas, 3.

QUESADA, J., "Martin Heidegger y la exigencia política del conocimiento: una raza dura", Isegoría, 43 (2010), 545-563.

RODRígueZ, R., "Naufragio, inhospitalidad, entrañas. María Zambrano ante Ortega y Heidegger", Aurora 12 (2011), 41-55.

ROJAS, A., "La ciudad inhóspita promovida por Martin Heidegger", Isegoría 47/juliodiciembre (2012), 499-517. 
ROJAS, A., Das Potenzlose, Olms, Hildesheim, 2014.

ROJAS, A., La Cuadratura. La última palabra del pensamiento ontológico de Heidegger, SPICUM, UMA, Málaga, 2009.

SAFRANSKI, R., Un maestro de Alemania. Heidegger y su tiempo, Tusquets, Barcelona, 1997, p. 276.

TAMAYO, L., “El colapso de Heidegger de 1945-1946. Reflexiones acerca del autor y su obra", L'école lacanienne de psychanalyse 3 (2001), pp. 161-184. 